Article

\title{
Cutting Performance Evaluation of the Coated Tools in High-Speed Milling of AISI 4340 Steel
}

\author{
Yuan Li, Guangming Zheng * , Xiang Cheng, Xianhai Yang, Rufeng $X u$ and Huaqiang Zhang \\ School of Mechanical Engineering, Shandong University of Technology; 266 West Xincun Road, \\ Zibo 255000, China; lysdut007@163.com (Y.L.); happychengx@163.com (X.C.); yxh@sdut.edu.cn (X.Y.); \\ xurufeng2003@126.com (R.X.); huaqiang.zhang@163.com (H.Z.) \\ * Correspondence: zhengguangming@sdut.edu.cn; Tel.: +86-533-2786972
}

Received: 3 September 2019; Accepted: 4 October 2019; Published: 7 October 2019

\begin{abstract}
The cutting performance of cutting tools in high-speed machining (HSM) is an important factor restricting the machined surface integrity of the workpiece. The HSM of AISI 4340 is carried out by using coated tools with TiN/TiCN/TiAlN multi-coating, TiAlN + TiN coating, TiCN + NbC coating, and AlTiN coating, respectively. The cutting performance evaluation of the coated tools is revealed by the chip morphology, cutting force, cutting temperature, and tool wear. The results show that the serration and shear slip of the chips become more clear with the cutting speed. The lower cutting force and cutting temperature are achieved by the TiN/TiCN/TiAlN multi-coated tool. The flank wear was the dominant wear form in the milling process of AISI 4340. The dominant wear mechanisms of the coated tools include the crater wear, coating chipping, adhesion, abrasion, and diffusion. In general, a TiN/TiCN/TiAlN multi-coated tool is the most suitable tool for high-speed milling of AISI 4340, due to the lower cutting force, the lower cutting temperature, and the high resistance of the element diffusion.
\end{abstract}

Keywords: cutting performance; coated tool; wear mechanism; chip morphology; AISI 4340

\section{Introduction}

The high-strength steel is widely applied in the aerospace because of its superior features. However, it is a typical difficult-to-cut material due to the high hardness, high plasticity, inferior thermal conductivity, and high toughness [1-3]. Therefore, it is particularly important to explore the tool materials and cutting parameters for achieving the highly-efficient machining of high-strength steel.

Coated tools are widely used in high-speed machining (HSM) of the difficult-to-cut materials, due to their high temperature stability, high hardness, high plasticity, high toughness, excellent wear resistance, and longer tool life $[4,5]$.

In order to study the high-speed cutting process of AISI 4340 steel, a great deal of research has been done on chip morphology, cutting force, cutting temperature, and a wear mechanism. The results show that the color of chips can reflect the cutting temperature and cutting speed when AISI 4340 steel is cut at high speed. The appearance of bright blue color chips indicates that the cutting speed is greater than $150 \mathrm{~m} /$ minute [6,7]. The chips are bright blue because the high cutting speeds result in high cutting temperatures, while the high cutting temperature is due to the high frictional forces between the flowing chips and the rake face [8,9]. The serrated chips are obtained when the AISI 4340 steel is cut at high speed, which can evaluate the cutting conditions. When the tooth-height of serrated chips exceeds 0.3 microns, it means that the cutting speed and the depth of cut, respectively, exceed $150 \mathrm{~m} /$ minute and $1.0 \mathrm{~mm}$ [10]. In addition, the short-broken chip is easy to gain at a high cutting speed condition [11]. The cutting parameters could be optimized by the 3D chip geometry driven analytical model [12]. As for the formation of serrated chips, it is related to crack propagation [13]. Other types of 
high-strength steel, such as AISI H13, also have serrated chips in the process of high-speed cutting [14]. In addition, the chips are closely related to the tool wear and the cutting force. The results show that the flow of chips can increase the probability of the coated tools' adhesion wear [15]. Additionally, the periodicity of the serrated chip is similar to the cyclicity of the cutting force [16].

The cutting force is an important response in the HSM process of AISI 4340 steel. On the one hand, the cutting force is influenced by the type of coated tool. It is suggested that the cutting force of the CVD (chemical vapor deposition) $-\mathrm{TiCN} / \mathrm{Al}_{2} \mathrm{O}_{3} / \mathrm{TiN}$ multi-coated tool is bigger than that of the PVD (physical vapor deposition) -TiAlN coated tool, due to the high friction [6]. On the other hand, the cutting parameters affect the cutting force. Based on the central composite design (CCD), the model of cutting force and cutting parameters is established. It is proven that the relationship between cutting force and cutting parameters is the quadratic polynomial [17]. Moreover, the influence of cutting speed on cutting force is more conspicuous [18]. In addition, based on the signal-to-noise ratio model, the cutting parameters are optimized by the cutting force [19].

The cutting performance of the coatings is influenced greatly by the cutting temperature [20]. In this respect, the prediction model of cutting temperature is established by the least square method [21]. This model indicates that the cutting temperature increases with the growth of cutting speed, feed per tooth, axial depth of cut, and radial depth cut. In order to predict the cutting temperature more accurately, the chip-tool interface temperature model is established [22]. In addition to establishing the model, it is also found that the thermal conductivity of the coating has an important effect on the cutting temperature. The lower thermal conductivity of $\mathrm{Ti}_{0.41} \mathrm{Al}_{0.59} \mathrm{~N}$ coating material and cemented carbide will generate the instantaneous thermal barrier effect [23], which can effectively reduce the cutting temperature. Moreover, the TiAlN coating can improve tool life, because of the lubricating ability and anti-adhesion properties [24].

Tool wear is an important indicator for evaluating the cutting performance. Therefore, the real-time monitoring of the flank wear is realized [25], while the normal force model is established to predict the flank wear of the coated tool [26]. Furthermore, the empirical wear volume-loss equation is proposed for abrasive wear, adhesive wear, and diffusion wear. In the aspect of wear type, the dominant wear form of coated carbide tool is the flank wear in HSM of AISI 4340 steel [27]. The dominant wear mechanisms of the coated tool are adhesion, abrasion, oxidation, and diffusion in HSM of high-strength steel $[6,28,29]$. The cutting-edge collapses and exposed tool substrate of the TiAlN coated tool and $\mathrm{TiCN} / \mathrm{Al}_{2} \mathrm{O}_{3} / \mathrm{TiN}$ multi-coated tool are common [30], and the AlTiN coated tool is more prone to chipping [31].

Based on the summary of current research on high-speed cutting of AISI 4340 steel, it was found that the main research contents are the prediction model of cutting force as well as the cutting temperature and tool wear, while the tool wear is studied. However, the most suitable coated tool for the HSM of AISI 4340 is not indicated. In the work, the TiN/TiCN/TiAlN multi-coated tool, TiAlN + TiN coated tool, TiCN $+\mathrm{NbC}$ coated tool, and AlTiN coated tool are used in the HSM of AISI 4340 steel. The cutting performance of the coated tools is evaluated by chip morphology, cutting force, cutting temperature, wear type, and wear mechanism in order to determine the most suitable coated tool for HSM of 4340 steel.

\section{Materials and Methods}

\subsection{Workpiece Material}

The workpiece material is AISI 4340 steel. The main chemical compositions of the workpiece are Ni $1.65 \%$, Cr 0.72\%, Mn 0.65\%, C 0.40\%, Mo 0.22\%, Si 0.15\%, P 0.01\%, and S 0.01\%. The tensile strength, yield strength, elongation, and reduction in area of AISI 4340 steel is $1462 \mathrm{MPa}, 1379 \mathrm{MPa}$, at $12 \%$ and $55 \%$, respectively [32]. The hardness of AISI 4340 steel is $42-44$ HRC, which is achieved by vacuum heat treatment. The heat treatment process is completed by the manufacturer of the workpiece material. 
This material is made by the Dongguan Chang'an Huaming Die Steel Business Department (Dongguan, China). The length, width, and height of the workpiece are $100 \mathrm{~mm}, 100 \mathrm{~mm}$, and $60 \mathrm{~mm}$, respectively.

\subsection{Cutting Tool Material}

There are four types of coated tools used in the experiments. The first one is a PVD-coated carbide tool with a single coating layer made of AlTiN, with a grade number of KC522M. The second one is a PVD-coated carbide tool with a composite coating layer made of TiAlN and TiN, with grade number of PR830. The third one is a multilayer PVD-coated carbide tool consisting of three layers made by different coating material ordered from the outer to the inner layer as: TiN, TiCN, and TiAIN, respectively, with grade number of ACM300. The last one is a PVD-coated ceramic tool with a composite coating layer made of TiCN and $\mathrm{NbC}$, with a grade number of TN100M. The tool hilt type of four coated tools is BT40-ER32-70. In addition, the cutter arbor types of KC522M and ACM300 is, respectively, 20A03R028A20ED10 and WEX2020E, while the cutter arbor type of PR830 and TN100M is MEC25-S20-11T. Furthermore, the cutting-edge angle of all coated tools is $90^{\circ}$. The cutting-edge inclination of $\mathrm{KC} 522 \mathrm{M}$ and $\mathrm{ACM} 300$ are, respectively, $15^{\circ}$ and $14^{\circ}$, while the cutting-edge inclination of PR830 and TN100M is $13^{\circ}$ [33-35]. The geometries of coating tools have been shown in Table 1 . The insert type and the diameter of cutter arbor $(d)$ are shown in Table 2.

Table 1. The geometries of coating tools.

\begin{tabular}{ccccc}
\hline Grade No. & $\begin{array}{c}\text { Length } \\
(\mathbf{m m})\end{array}$ & $\begin{array}{c}\text { Width } \\
\mathbf{( m m )}\end{array}$ & $\begin{array}{c}\text { Thickness } \\
\mathbf{( m m})\end{array}$ & $\begin{array}{c}\text { Nose Radius } \\
(\mathbf{m m})\end{array}$ \\
\hline KC522M & 12.05 & 6.75 & 3.75 & 0.40 \\
PR830 & 11.00 & 6.70 & 3.80 & 0.80 \\
ACM300 & 12.00 & 7.00 & 3.58 & 0.80 \\
TN100M & 11.00 & 6.70 & 3.80 & 0.80 \\
\hline
\end{tabular}

Table 2. Insert type and the diameter of cutter arbor.

\begin{tabular}{cccc}
\hline Grade No. & Insert Type & $\begin{array}{c}\text { Diameter of Cutter Arbor } \\
\boldsymbol{d} \mathbf{( \mathbf { m } )}\end{array}$ & Manufacturer \\
\hline KC522M & EDCT10T304PDERLD & 20 & Kennametal, PA, USA \\
PR830 & BDMT-11T308ER-JT & 25 & Kyocera, Japan \\
ACM300 & AXMT 123508PEER-E & 20 & Sumitomo, Japan \\
TN100M & BDMT-11T308ER-JT & 25 & Kyocera, Japan \\
\hline
\end{tabular}

\subsection{Experimental Design}

The dry down milling tests of AISI 4340 steel are carried out by the NC milling machine center with a 3-axis, which is made in Doosan Machine Tools Co., Ltd. (Yantai, China), and model DNM-415, with a maximum speed of $12,000 \mathrm{r} / \mathrm{min}$. To avoid the influence of the inserts, only one insert is used in the milling process. The cutting length for every cutting parameter is $300 \mathrm{~mm}$. The cutting force is measured by the cutting force measurement system (Model: 9257B, Kistler, Switzerland), while the cutting temperature is measured by the thermal infrared imager (Model: A300, FLIR, Portland, OR, USA). In the process of temperature measurement, the material of the workpiece is unchanged, and the material of the coated tool is changed. To avoid the influence of the coated tool on temperature measurement, the temperature reflected by the workpiece (or chip) is selected as cutting temperature. Therefore, only the thermal diffusivity of the workpiece is set at 0.95 . FLIR A300 is automatically calibrated, while the resolution and frame speed of it is $320 \times 240$ pixels and $30 \mathrm{~Hz}$. The experimental design of the high-speed milling of AISI 4340 steel and the cutting parameters is shown in Figure 1 and Table 3, respectively. According to Table 3, each coated tool is tested in 40 different sets of cutting parameters. Furthermore, three tests were performed for each set of cutting parameters, and the average of three results is taken as experimental data. The tool wear mechanisms and the chip 
morphology are observed by a scanning electron microscope (SEM, Model: Quanta 250, FEI, Hillsboro, OR, USA). Chemical elements of the worn-out tools are detected by the energy dispersive spectrometer (EDS, Model: Quanta 250, FEI, Hillsboro, OR, USA).

Table 3. Cutting parameters.

\begin{tabular}{|c|c|c|c|c|}
\hline No. & $\begin{array}{c}\text { Cutting Speed } \\
v_{\mathrm{c}}(\mathrm{m} / \mathrm{min})\end{array}$ & $\begin{array}{l}\text { Feed Per Tooth } \\
f_{\mathrm{z}}(\mathrm{mm} / \mathrm{z})\end{array}$ & $\begin{array}{l}\text { Axial Depth of Cut } \\
\qquad a_{\mathrm{p}}(\mathrm{mm})\end{array}$ & $\begin{array}{c}\text { Radial Depth Cut } \\
a_{\mathrm{e}}(\mathrm{mm})\end{array}$ \\
\hline 1 & 280 & 0.02 & 0.2 & 2 \\
\hline 2 & 280 & 0.02 & 0.2 & 4 \\
\hline 3 & 280 & 0.02 & 0.4 & 2 \\
\hline 4 & 280 & 0.02 & 0.4 & 4 \\
\hline 5 & 280 & 0.04 & 0.2 & 2 \\
\hline 6 & 280 & 0.04 & 0.2 & 4 \\
\hline 7 & 280 & 0.04 & 0.4 & 2 \\
\hline 8 & 280 & 0.04 & 0.4 & 4 \\
\hline 9 & 320 & 0.02 & 0.2 & 2 \\
\hline 10 & 320 & 0.02 & 0.2 & 4 \\
\hline 11 & 320 & 0.02 & 0.4 & 2 \\
\hline 12 & 320 & 0.02 & 0.4 & 4 \\
\hline 13 & 320 & 0.04 & 0.2 & 2 \\
\hline 14 & 320 & 0.04 & 0.2 & 4 \\
\hline 15 & 320 & 0.04 & 0.4 & 2 \\
\hline 16 & 320 & 0.04 & 0.4 & 4 \\
\hline 17 & 360 & 0.02 & 0.2 & 2 \\
\hline 18 & 360 & 0.02 & 0.2 & 4 \\
\hline 19 & 360 & 0.02 & 0.4 & 2 \\
\hline 20 & 360 & 0.02 & 0.4 & 4 \\
\hline 21 & 360 & 0.04 & 0.2 & 2 \\
\hline 22 & 360 & 0.04 & 0.2 & 4 \\
\hline 23 & 360 & 0.04 & 0.4 & 2 \\
\hline 24 & 360 & 0.04 & 0.4 & 4 \\
\hline 25 & 400 & 0.02 & 0.2 & 2 \\
\hline 26 & 400 & 0.02 & 0.2 & 4 \\
\hline 27 & 400 & 0.02 & 0.4 & 2 \\
\hline 28 & 400 & 0.02 & 0.4 & 4 \\
\hline 29 & 400 & 0.04 & 0.2 & 2 \\
\hline 30 & 400 & 0.04 & 0.2 & 4 \\
\hline 31 & 400 & 0.04 & 0.4 & 2 \\
\hline 32 & 400 & 0.04 & 0.4 & 4 \\
\hline 33 & 440 & 0.02 & 0.2 & 2 \\
\hline 34 & 440 & 0.02 & 0.2 & 4 \\
\hline 35 & 440 & 0.02 & 0.4 & 2 \\
\hline 36 & 440 & 0.02 & 0.4 & 4 \\
\hline 37 & 440 & 0.04 & 0.2 & 2 \\
\hline 38 & 440 & 0.04 & 0.2 & 4 \\
\hline 39 & 440 & 0.04 & 0.4 & 2 \\
\hline 40 & 440 & 0.04 & 0.4 & 4 \\
\hline
\end{tabular}




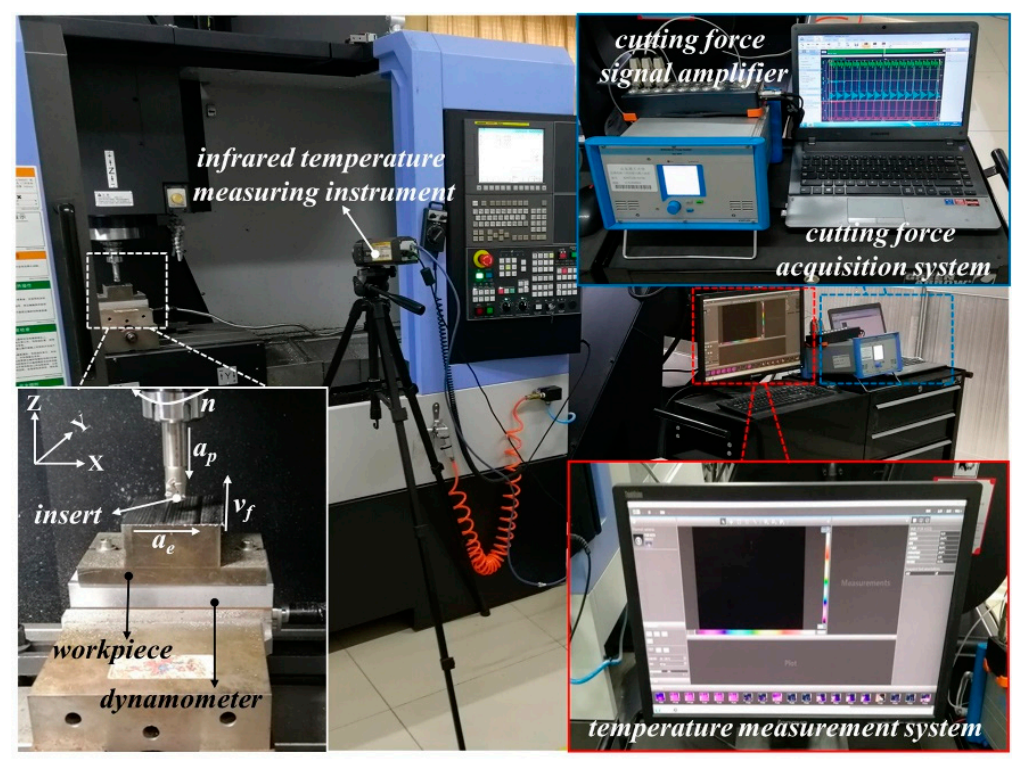

Figure 1. Experimental design of the high-speed milling of AISI 4340 steel.

\section{Results and Discussion}

\subsection{Chip Morphology}

The micrographs of chip surfaces flowing from the rake face at $v_{\mathrm{c}}=440 \mathrm{~m} / \mathrm{min}, f_{\mathrm{z}}=0.04 \mathrm{~mm} / \mathrm{z}$, $a_{\mathrm{p}}=0.4 \mathrm{~mm}$, and $a_{\mathrm{e}}=4 \mathrm{~mm}$ are presented in Figure 2. It is found that the crack caused by the AlTiN coated tool and the TiAlN + TiN coated tool is more serious than that caused by the TiN/TiCN/TiAlN multi-coated tool. The TiCN $+\mathrm{NbC}$ coated tool acquires the dense burrs chip. It is indirectly reflected that the tool wear of TiCN $+\mathrm{NbC}$ coated tool is enormous. As can be seen in Figure 2a, the micrograph of chip surfaces got by the TiN/TiCN/TiAlN multi-coated tool is the smoothest, which is accompanied with no clear burrs. It is suggested that the tool wear of TiN/TiCN/TiAlN multi-coating is smaller than that of the other three tools. Figure 3 shows the micrographs of chip surfaces away from the rake face at $v_{\mathrm{c}}=360 \mathrm{~m} / \mathrm{min}, f_{\mathrm{z}}=0.04 \mathrm{~mm} / \mathrm{z}, a_{\mathrm{p}}=0.4 \mathrm{~mm}$, and $a_{\mathrm{e}}=4 \mathrm{~mm}$, (a) TiN/TiCN/TiAlN multi-coating, (b) AlTiN coating, (c) TiAlN + TiN composite coating, and (d) TiCN + NbC composite coating. As can be seen from Figure 3, the texture of the chip surface has been curved. This proves the existence of plastic deformation. However, the difference in plastic deformation of the chip surface obtained by the four coated tools is not clear. It can be concluded that the serrated degree of chips obtained by four coated tools is different under the same cutting parameter. The formation of the serrated chips is the result of stress hardening caused by cutting force and softening caused by the cutting temperature. When the softening effect is strengthened, the stress that prevents the deformation of material will be reduced. Until the softening exceeds the stress hardening, it will cause local deformation and then produce serrated chips. In addition, the chip serration shape of the TiN/TiCN/TiAlN multi-coated tool and AlTiN coated tool was significant and uniform when compared to the TiAlN + TiN coated tool and the $\mathrm{TiCN}+\mathrm{NbC}$ coated tool. This shows that stress hardening and softening of the TiN/TiCN/TiAlN multi-coated tool and the AlTiN coated tool is more stable than that of the TiAlN + TiN coated tool and the $\mathrm{TiCN}+\mathrm{NbC}$ coated tool. It is also found that the crack propagation of the TiAlN + TiN coated tool and the TiCN $+\mathrm{NbC}$ coated tool is more serious than that of the TiN/TiCN/TiAlN multi-coated tool and the AlTiN coated tool. This indicates that the cutting force of the TiAlN + TiN coated tool and the $\mathrm{TiCN}+\mathrm{NbC}$ coated tool is larger than that of the TiN/TiCN/TiAlN multi-coated tool and the AlTiN coated tool. This occurs because the severe crack propagation is caused by large cutting forces and alternating mechanical loads. 

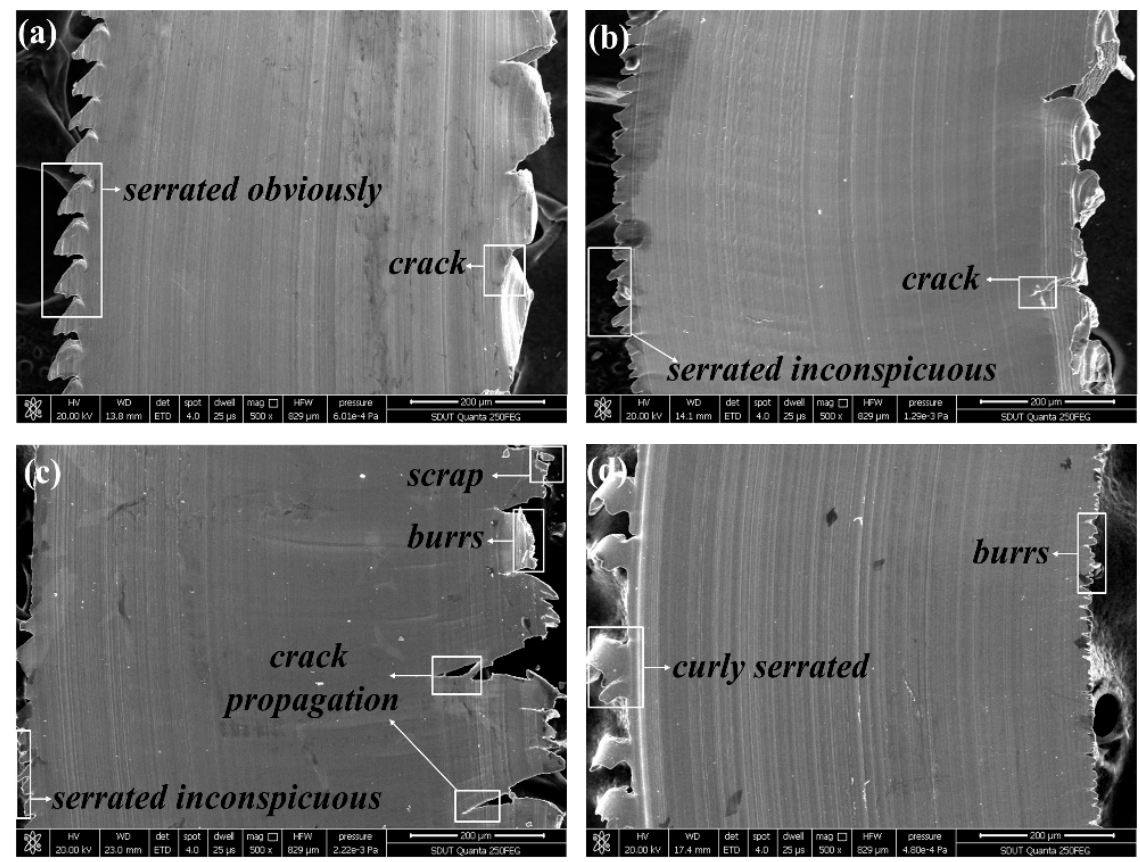

Figure 2. Micrographs of chip surfaces flowing from rake face at $v_{\mathrm{C}}=440 \mathrm{~m} / \mathrm{min}, f_{\mathrm{z}}=0.04 \mathrm{~mm} / \mathrm{z}$, $a_{\mathrm{p}}=0.4 \mathrm{~mm}$, and $a_{\mathrm{e}}=4 \mathrm{~mm}$, (a) TiN/TiCN/TiAlN multi-coating, (b) AlTiN coating, (c) TiAlN + TiN composite coating, and (d) $\mathrm{TiCN}+\mathrm{NbC}$ composite coating.
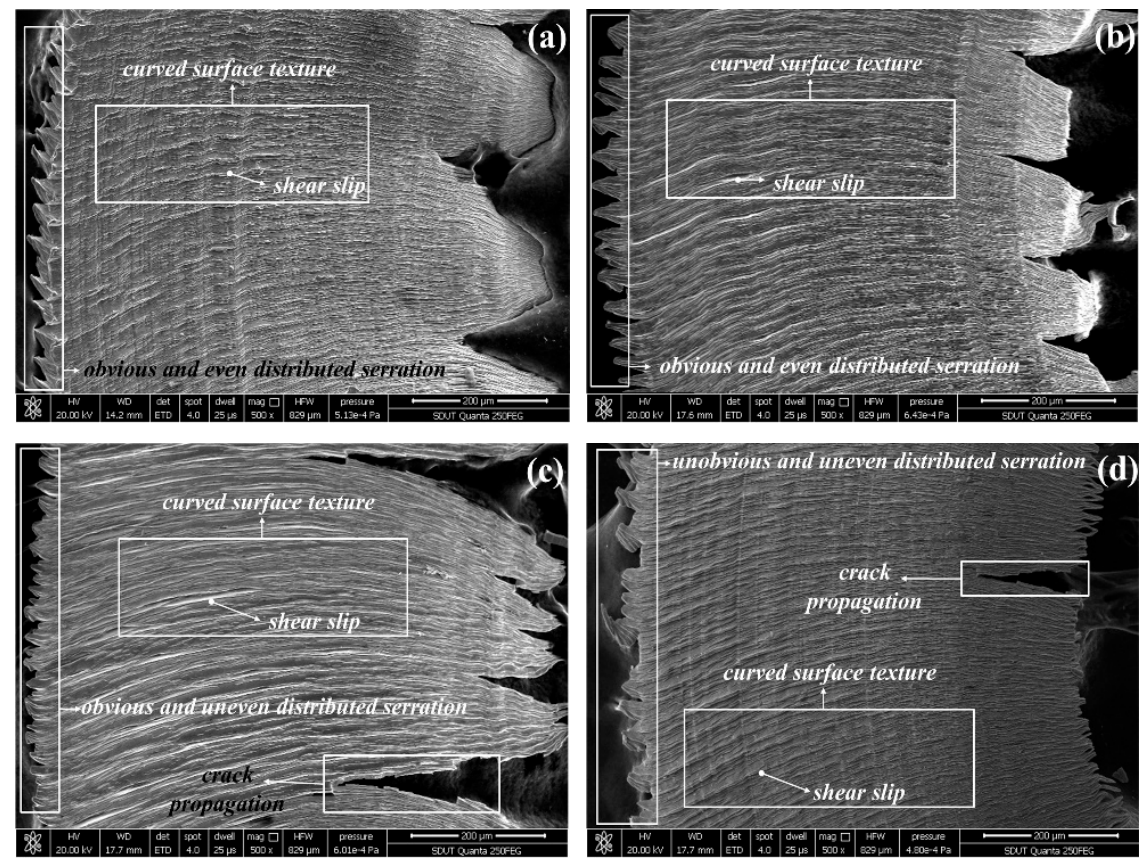

Figure 3. Micrographs of chip surfaces away from the rake face at $v_{\mathrm{c}}=360 \mathrm{~m} / \mathrm{min}, f_{\mathrm{z}}=0.04 \mathrm{~mm} / \mathrm{z}$, $a_{\mathrm{p}}=0.4 \mathrm{~mm}$, and $a_{\mathrm{e}}=4 \mathrm{~mm},(\mathbf{a}) \mathrm{TiN} / \mathrm{TiCN} / \mathrm{TiAlN}$ multi-coating, (b) AlTiN coating, (c) TiAlN $+\mathrm{TiN}$ composite coating, and (d) $\mathrm{TiCN}+\mathrm{NbC}$ composite coating.

\subsection{Cutting Force}

The value of cutting force $\left(F_{\mathrm{x}}, F_{\mathrm{y}}, F_{\mathrm{z}}\right)$ varies with time. Therefore, the maximum force is considered to analyze the effect of coatings and cutting parameters on the cutting force. Figures 4 and 5 show the effect of coatings on cutting force at different cutting parameters, from which can be seen that the $F_{\mathrm{Z}}$ (axial force) is the highest component of the cutting force. It illustrates that the $F_{\mathrm{Z}}$ is the main 
component of the cutting force. This is due to the extrusion and friction between the flank face of the coated tool and workpiece being greater than that between the rank face of the coated tool and workpiece. This is also proven by the fact that the main wear form is the flank wear. Moreover, the cutting force $\left(F_{\mathrm{x}}, F_{\mathrm{y}}, F_{\mathrm{z}}\right)$ is improved with cutting speed when the $f_{\mathrm{z}}, a_{\mathrm{p}}, a_{\mathrm{e}}$, and coating material are maintaining constant, which can also be seen from Figures 4 and 5 . In addition, it is observed from Figures $4 \mathrm{a}$ and $5 \mathrm{a}$ that the cutting force is increased with $f_{\mathrm{z}}, a_{\mathrm{p}}$, and $a_{\mathrm{e}}$, when the cutting speed and coating material is taking the constant value. As can be observed in Figures 4 and 5, the cutting force of the TiN/TiCN/TiAlN multi-coated tool is the minimum magnitude at the same cutting parameter. Therefore, for all of that, the TiN/TiCN/TiAlN multi-coated tool is the most suitable tool for milling AISI 4340 steel to achieve the smallest cutting force.
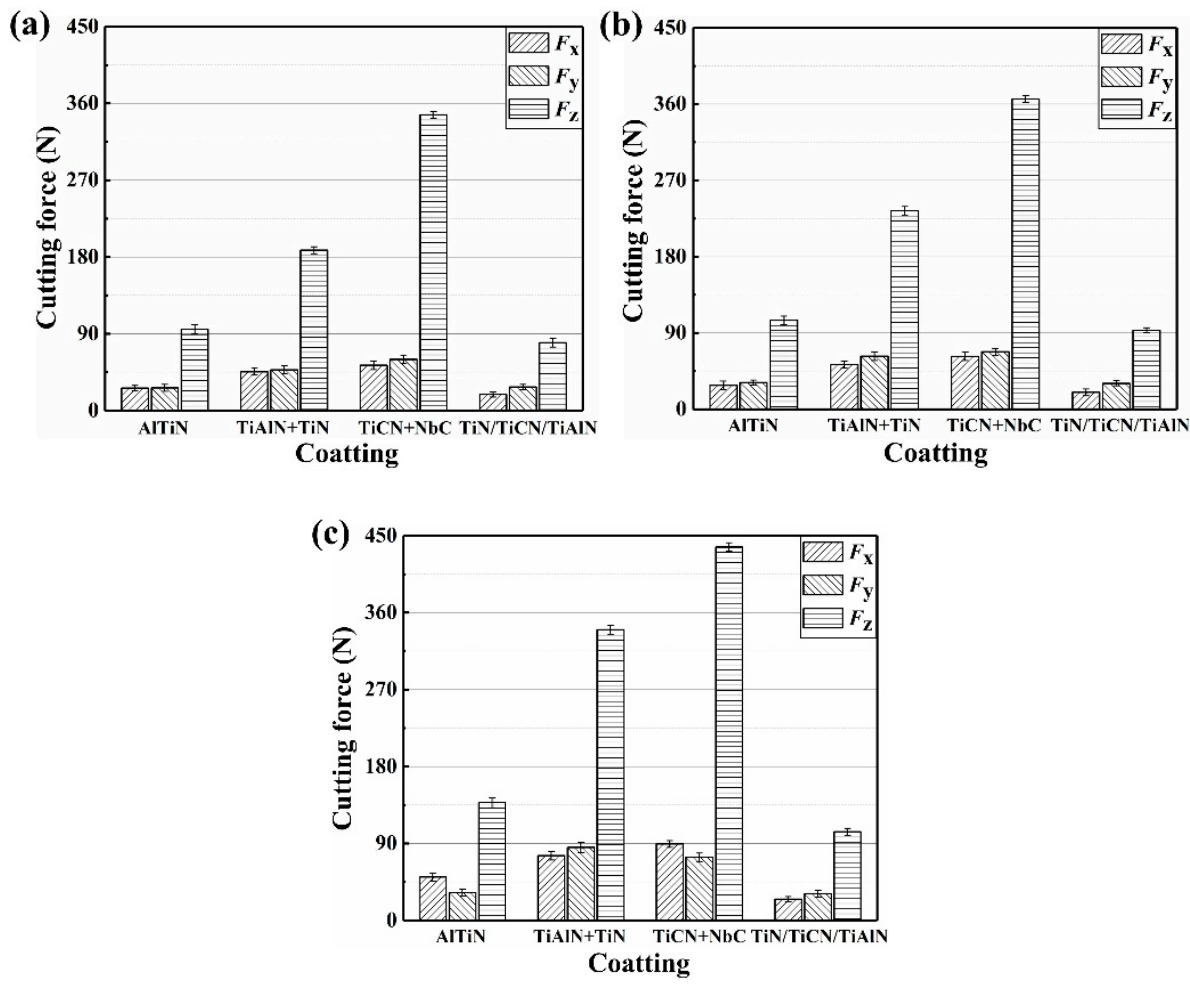

Figure 4. Effect of coatings on cutting force at (a) $v_{\mathrm{c}}=280 \mathrm{~m} / \mathrm{min},(\mathbf{b}) v_{\mathrm{c}}=360 \mathrm{~m} / \mathrm{min}$, and (c) $v_{\mathrm{c}}=$ $440 \mathrm{~m} / \mathrm{min}, f_{\mathrm{z}}=0.02 \mathrm{~mm} / \mathrm{z}, a_{\mathrm{p}}=0.2 \mathrm{~mm}$, and $a_{\mathrm{e}}=2 \mathrm{~mm}$.
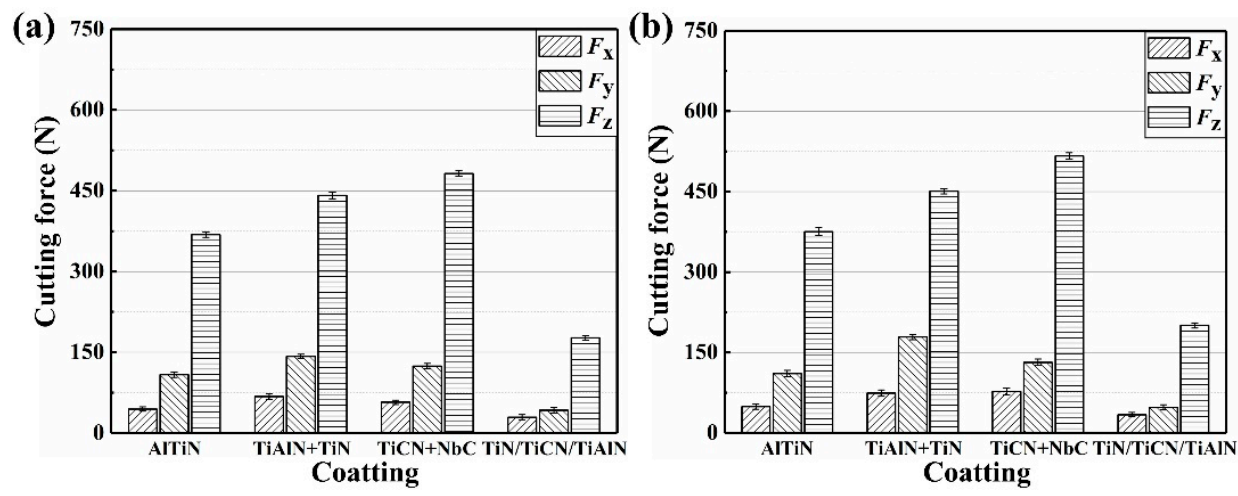

Figure 5. Cont. 


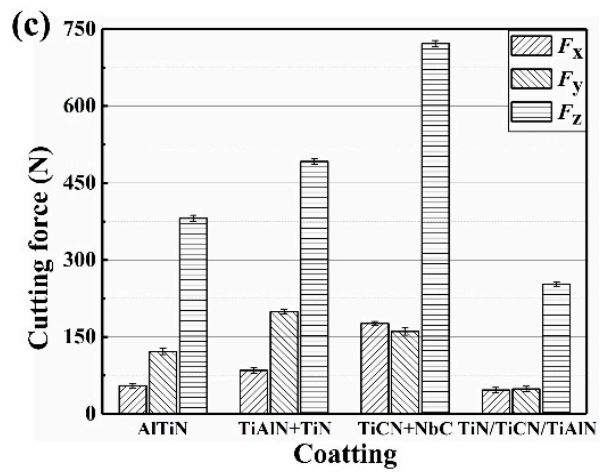

Figure 5. Effect of coatings on cutting force at (a) $v_{\mathrm{c}}=280 \mathrm{~m} / \mathrm{min},(\mathbf{b}) v_{\mathrm{c}}=360 \mathrm{~m} / \mathrm{min}$, and (c) $v_{\mathrm{c}}=$ $440 \mathrm{~m} / \mathrm{min}, f_{\mathrm{z}}=0.04 \mathrm{~mm} / \mathrm{z}, a_{\mathrm{p}}=0.4 \mathrm{~mm}$, and $a_{\mathrm{e}}=4 \mathrm{~mm}$.

\subsection{Cutting Temperature}

The infrared thermal image of the high-speed milling experiment is exhibited in Figure 6. The red triangle is an automatic function of the temperature measurement system to mark the highest temperature point. In the process of temperature measurement, the temperature measurement system automatically displays a red triangle at the highest temperature in the area. The red triangle appears at the point where the tip is in contact with the workpiece, and it is concluded that the highest temperature is acquired at the contact position between the tip and the workpiece. Then, the maximum value of the cutting temperature in the machining area was investigated in the study.

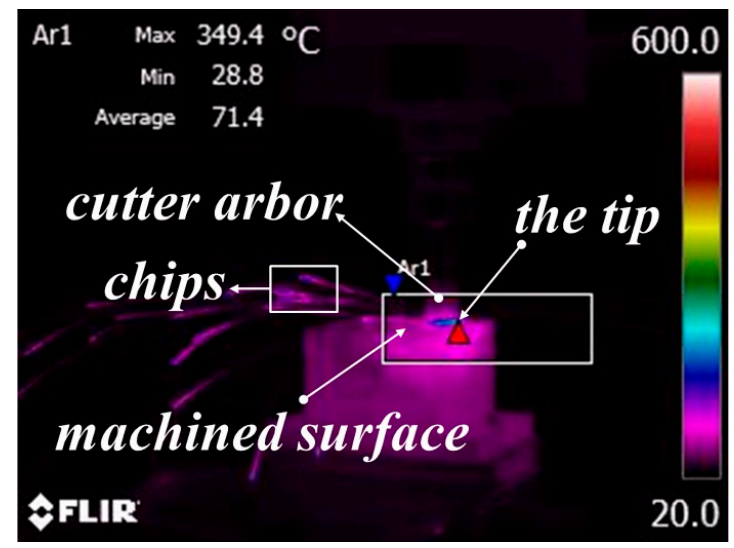

Figure 6. Infrared thermal image of the high-speed milling experiment.

Figure 7 presents the effect of cutting parameters on cutting temperature of the coated tools. The cutting temperature of TiAlN + TiN coated tool changes with the cutting parameters, as shown in Figure 7a. For the lines A and B in Figure 7a, the cutting temperature is slightly raised at $v_{c}=280 \sim 320$ $\mathrm{m} / \mathrm{min}$ and $v_{\mathrm{C}}=400 \sim 440 \mathrm{~m} / \mathrm{min}$. Additionally, the growth rate of cutting temperature is improved greatly at $v_{\mathrm{c}}=320 \sim 400 \mathrm{~m} / \mathrm{min}$. However, the value of line $\mathrm{B}$ is larger than that of line $\mathrm{A}$, because of the improvement of the feed per tooth from $0.02 \mathrm{~mm} / \mathrm{z}$ to $0.04 \mathrm{~mm} / \mathrm{z}$. The cutting temperature of Line $C$ in Figure $7 \mathrm{a}$ increases gradually when $v_{\mathrm{c}}$ accelerates from $320 \mathrm{~m} /$ minute to $440 \mathrm{~m} / \mathrm{minute}$. In addition, the cutting temperature of line $\mathrm{D}$ is fluctuant and sharply increased with cutting speed at $a_{\mathrm{p}}=0.4 \mathrm{~mm}$.

The cutting temperature of $\mathrm{TiCN}+\mathrm{NbC}$ coated tool changes with the cutting parameters, as shown in Figure 7b. For the lines E, F, and G, the cutting temperature slowly increases with cutting speed. However, the value of line $\mathrm{H}$ is clearly greater than that of lines $\mathrm{E}, \mathrm{F}$, and $\mathrm{G}$. This is due to the increase of $a_{\mathrm{p}}$ from $0.2 \mathrm{~mm}$ to $0.4 \mathrm{~mm}$. It is shown that the effect of doubling $a_{\mathrm{p}}$ on cutting temperature is greater than doubling $f_{\mathrm{z}}$ or $a_{\mathrm{e}}$ on cutting temperature under the same cutting speed for the TiCN + $\mathrm{NbC}$ coated tool. 

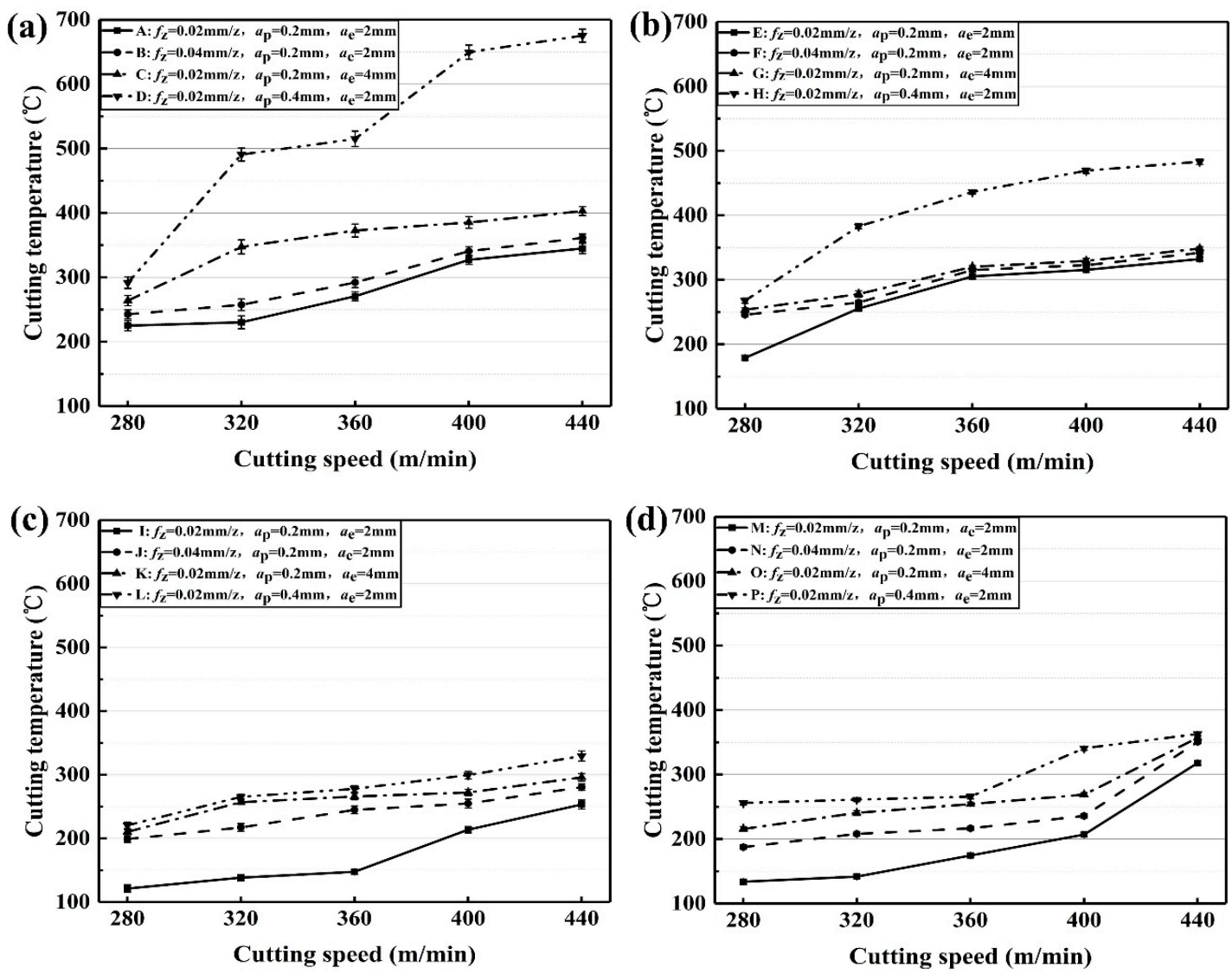

Figure 7. Effect of cutting parameters on cutting temperature, (a) TiAlN + TiN coating, (b) $\mathrm{TiCN}+\mathrm{NbC}$ coating, (c) TiN/TiCN/TiAlN multi-coating, and (d) AlTiN coating.

The cutting temperature of the TiN/TiCN/TiAlN coated tool changes with cutting parameters, as shown in Figure 7c. The cutting temperature of Line I has a slight rise at $v_{\mathrm{c}}=280 \sim 360 \mathrm{~m} / \mathrm{min}$. Afterward, it rapidly increases at $v_{\mathrm{c}}=360 \sim 440 \mathrm{~m} / \mathrm{min}$. The cutting temperature of Line $\mathrm{J}$ is improved somewhat linearly with cutting speed. In addition, the cutting temperature of Line $\mathrm{K}$ rises sharply at $v_{\mathrm{C}}=280 \sim 320 \mathrm{~m} / \mathrm{min}$, and increases slowly at $v_{\mathrm{C}}=320 \sim 440 \mathrm{~m} / \mathrm{min}$.

The cutting temperature of the AlTiN coated tool changes with cutting parameters, as shown in Figure $7 \mathrm{~d}$. For line $\mathrm{M}$, the value of the cutting temperature is slightly raised at $v_{\mathrm{C}}=280 \sim 320 \mathrm{~m} / \mathrm{minute}$. As $v_{\mathrm{c}}$ increases from 320 to $400 \mathrm{~m} / \mathrm{min}$, the cutting temperature rapidly increases. When the increase of $v_{\mathrm{c}}$ grows from 400 to $440 \mathrm{~m} /$ minute, the rise in cutting temperature grows sharply. For lines $\mathrm{N}, \mathrm{O}$, and $\mathrm{P}$, the cutting temperature increases with the increase of $f_{\mathrm{z}}, a_{\mathrm{p}}$, or $a_{\mathrm{e}}$. In addition, the value of cutting temperature increases slightly.

In general, the cutting temperature can be improved with the increase of the cutting parameters. As the cutting parameters increase, the volume of material removed per unit time is improved. As a result, the plastic deformation of the workpiece material and chip becomes more severe. The energy generated by plastic deformation is converted into cutting heat, which leads to the rise of the temperature in the cutting area. At the same time, the influence of cutting temperature on the thermal conductivity of AISI 4340 steel is considered, because the thermal conductivity of AISI 4340 steel is reduced with the increase of cutting temperature [36]. The low thermal conductivity can lead to the reduction of heat dissipation and the increase of cutting temperature.

On the other hand, at the same cutting parameter, the cutting temperature of the TiN/TiCN/TiAlN multi-coated tool is lower than that of the other coated tool, which can be seen in Figure 7 . The TiN/TiCN/TiAlN coating is a multi-layer PVD-coating, and AlTiN coating is a single PVD-coating, while the TiAlN + TiN coating and TiCN + NbC coating are the composite PVD-coating. The order 
of the thermal conductivity is TiCN coating $>$ TiN coating $>$ TiAlN coating [37]. However, only the $\mathrm{TiN} / \mathrm{TiCN} / \mathrm{TiAlN}$ multi-coated tool has the middle layer of $\mathrm{TiCN}$. TiCN, as the middle layer, increases the heat dissipation of the TiN/TiCN/TiAlN multi-coated tool. When the heat is transferred to the TiCN layer, the heat is rapidly dissipated due to the high thermal conductivity of TiCN. Therefore, the cutting temperature of the TiN/TiCN/TiAlN multi-coated tool is lower than that of the other coated tool.

\subsection{Wear Type and Wear Mechanism}

Figure 8 presents the rake wear and flank wear at $v_{\mathrm{c}}=280 \mathrm{~m} / \mathrm{min}, f_{\mathrm{z}}=0.02 \mathrm{~mm}, a_{\mathrm{p}}=0.2 \mathrm{~mm}$, and $a_{\mathrm{e}}=2 \mathrm{~mm}$. For the TiAlN $+\mathrm{TiN}$ coated tool and TiCN $+\mathrm{NbC}$ coated tool, the wear of the rake face is less than that of the flank face. Therefore, the flank wear is a dominant wear type in high-speed milling of AISI 4340 steel.
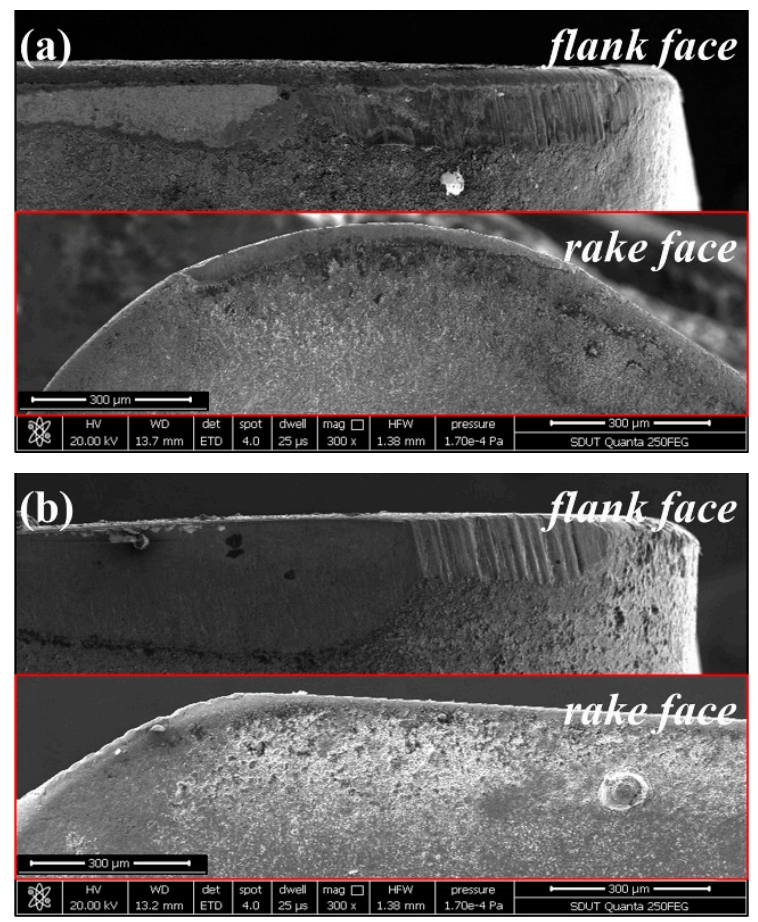

Figure 8. Rake wear and flank wear at $v_{\mathrm{c}}=280 \mathrm{~m} / \mathrm{min}, f_{\mathrm{z}}=0.02 \mathrm{~mm}, a_{\mathrm{p}}=0.2 \mathrm{~mm}$, and $a_{\mathrm{e}}=2 \mathrm{~mm}$, (a) TiAlN + TiN coating, and (b) TiCN $+\mathrm{NbC}$ coating.

The SEM micrograph of tool wear at $v_{\mathrm{c}}=280 \mathrm{~m} / \mathrm{min}, f_{\mathrm{z}}=0.02 \mathrm{~mm}, a_{\mathrm{p}}=0.2 \mathrm{~mm}$, and $a_{\mathrm{e}}=2 \mathrm{~mm}$ is shown in Figure 9, from which can be seen that the flank wear width of the TiN/TiCN/TiAlN multi-coated tool is the minimum. The micro crack on the tip and the coating chipping are found on the worn surface of the AlTiN coated tool (Figure 9b). As can be observed in Figure 9a,c, the flank wear width got by TiAlN + TiN coated tool is more serious than that got by the TiN/TiCN/TiAlN multi-coated tool. The coating chipping of the TiAlN + TiN coated tool is also observed on the flank face (Figure 9c). For the $\mathrm{TiCN}+\mathrm{NbC}$ coated tool, the flank wear width is the maximum and the chip bonding and abrasive wear is also found on the flank face, as can be illustrated in Figure 9d. Figure 10 shows the SEM micrograph of tool wear at $v_{\mathrm{c}}=440 \mathrm{~m} / \mathrm{min}, f_{\mathrm{z}}=0.04 \mathrm{~mm}, a_{\mathrm{p}}=0.4 \mathrm{~mm}$, and $a_{\mathrm{e}}=4 \mathrm{~mm}$. For the TiN/TiCN/TiAlN multi-coated tool, the damaged coating is presented on the flank face (Figure 10a). For the AlTiN coated tool, the collapse and tear of coating are observed as the dominant wear type (Figure 10b). In addition, a typical chip bonding is observed on the flank face of the AlTiN coating. Additionally, the micro crack and chip bonding are observed on the worn surface of the TiAlN + TiN coated tool (Figure 10c). As can be exhibited in Figure 10d, the tool failure of the $\mathrm{TiCN}+\mathrm{NbC}$ coated tool is mainly caused by coating chipping, crack, and sharp collapse. 

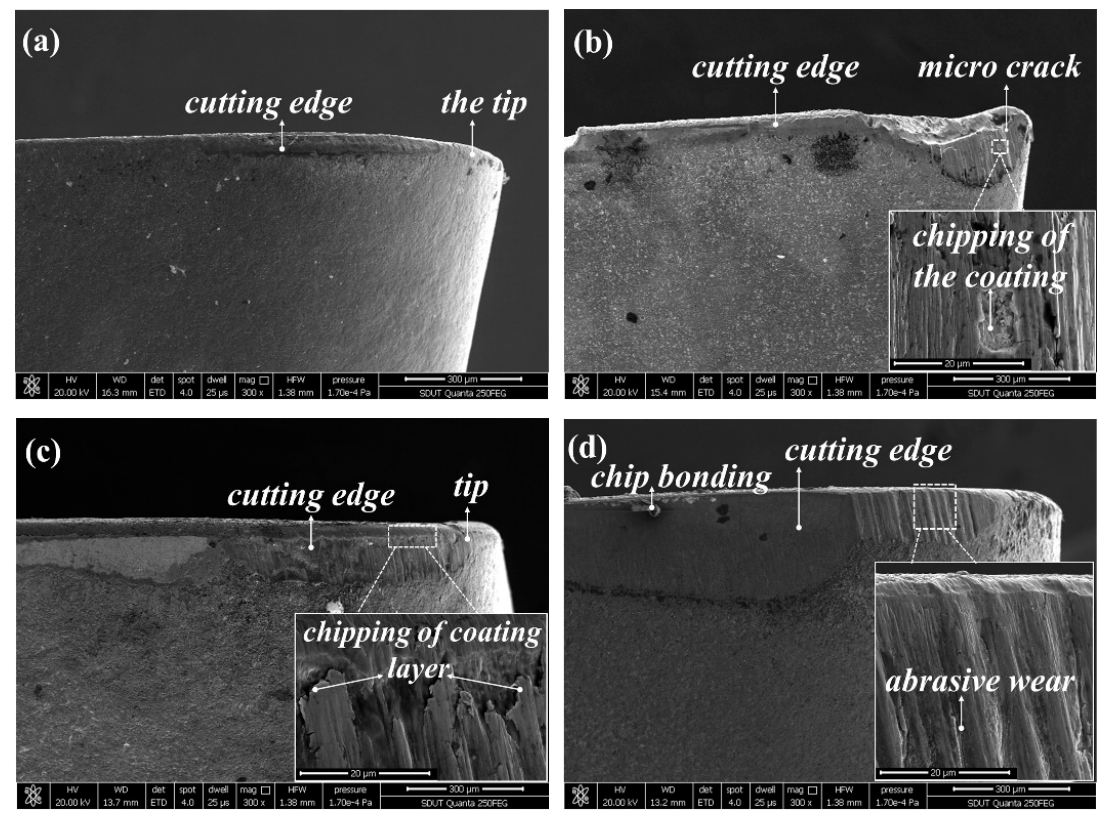

Figure 9. SEM micrograph of tool wear at $v_{\mathrm{C}}=280 \mathrm{~m} / \mathrm{min}, f_{\mathrm{z}}=0.02 \mathrm{~mm}, a_{\mathrm{p}}=0.2 \mathrm{~mm}$, and $a_{\mathrm{e}}=2 \mathrm{~mm}$, (a) TiN/TiCN/TiAlN multi-coated tool, (b) AlTiN coated tool, (c) TiAlN + TiN coated tool, and (d) TiCN $+\mathrm{NbC}$ coated tool.
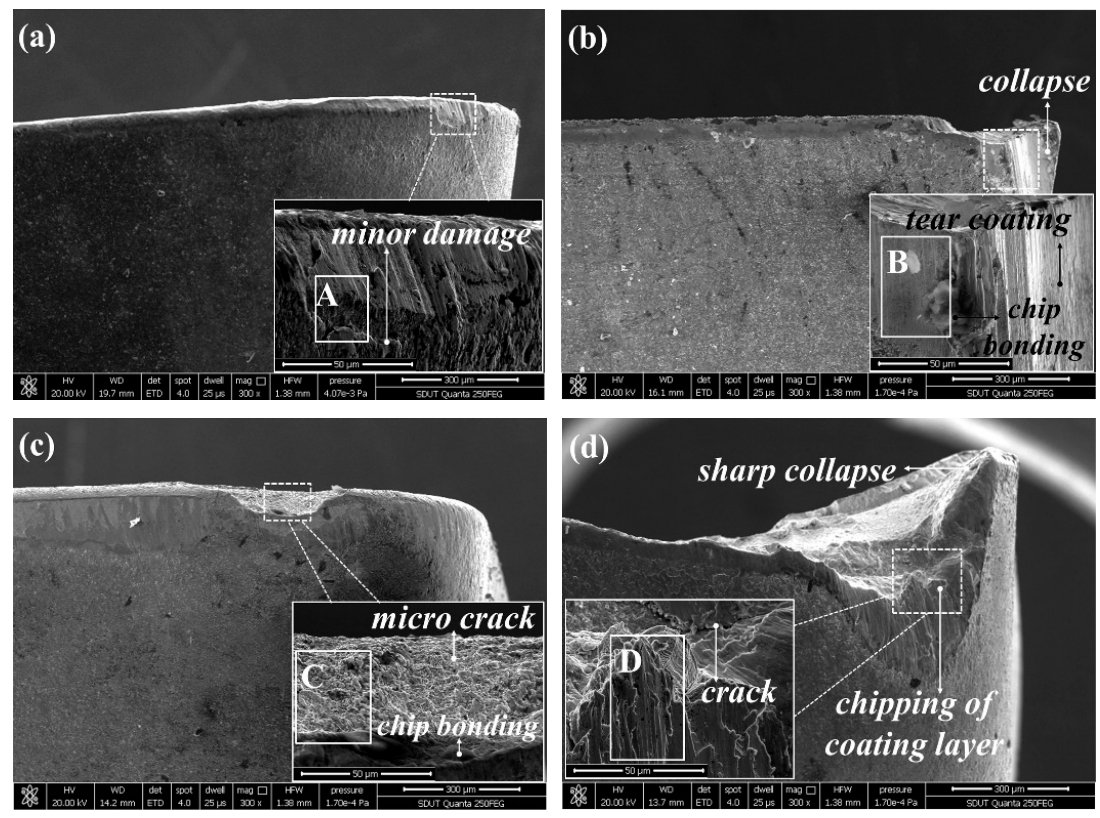

Figure 10. SEM micrograph of tool wear at $v_{\mathrm{c}}=440 \mathrm{~m} / \mathrm{min}, f_{\mathrm{z}}=0.04 \mathrm{~mm}, a_{\mathrm{p}}=0.4 \mathrm{~mm}$, and $a_{\mathrm{e}}=4 \mathrm{~mm}$, (a) TiN/TiCN/TiAlN multi-coated tool, (b) AlTiN coated tool, (c) TiAlN + TiN coated tool, and (d) TiCN $+\mathrm{NbC}$ coated tool.

As can be seen in Figures 9 and 10, the sharpening, chipping, crack, and collapse is not found on the worn surface of the TiN/TiCN/TiAlN multi-coated tool. It is inferred that the wear-resistance and shock resistance of the TiN/TiCN/TiAlN multi-coated tool is better than that of the other three tools. The chipping of the coating layer and abrasive wear is not found on the flank surface of the TiN/TiCN/TiAlN multi-coated tool. The coating adhesion and cohesion between coating and the substrate of the TiN/TiCN/TiAlN multi-coated tool is compared to that of the other coated tool. 
In addition, the TiN/TiCN/TiAlN multi-coated tool has no serious coating damage, which can also prove the result.

The EDS analysis at $v_{\mathrm{c}}=440 \mathrm{~m} / \mathrm{min}, f_{\mathrm{z}}=0.04 \mathrm{~mm} / \mathrm{z}, a_{\mathrm{p}}=0.4 \mathrm{~mm}$, and $a_{\mathrm{e}}=4 \mathrm{~mm}$ is shown in Figure 11. For the TiN/TiCN/TiAlN multi-coated tool (Figure 11a), the proportion of the Ti element in the coating material is higher. It is suggested that the coating is relatively complete. This is consistent with the result of tool wear (Figure 10a). However, the proportion of the Ti element in the other three coating materials is lower, as shown in Figure $11 \mathrm{~b}-\mathrm{d}$. It is proven that the coating is severely damaged. This is also shown by the tool wear, as shown in Figure 10b-d. Additionally, the oxygen element is present on the flank face of the four coated tools. It is demonstrated that the oxidative wear is an important factor leading to tool failure.

(a)

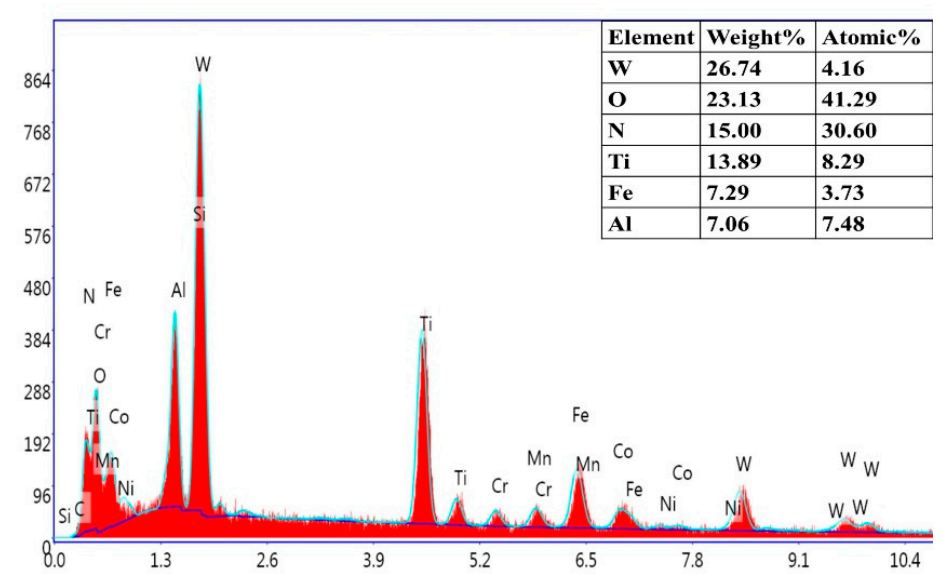

(b)

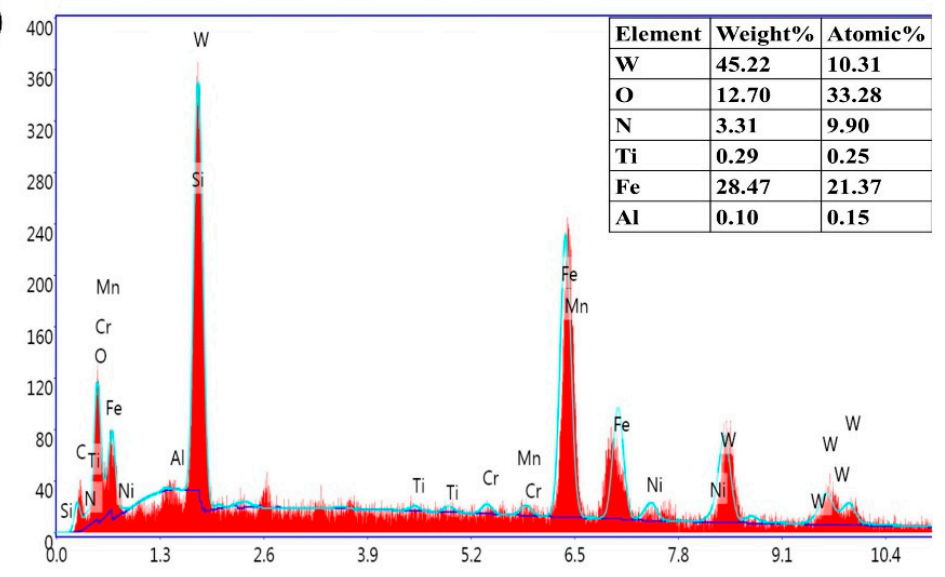

(c)

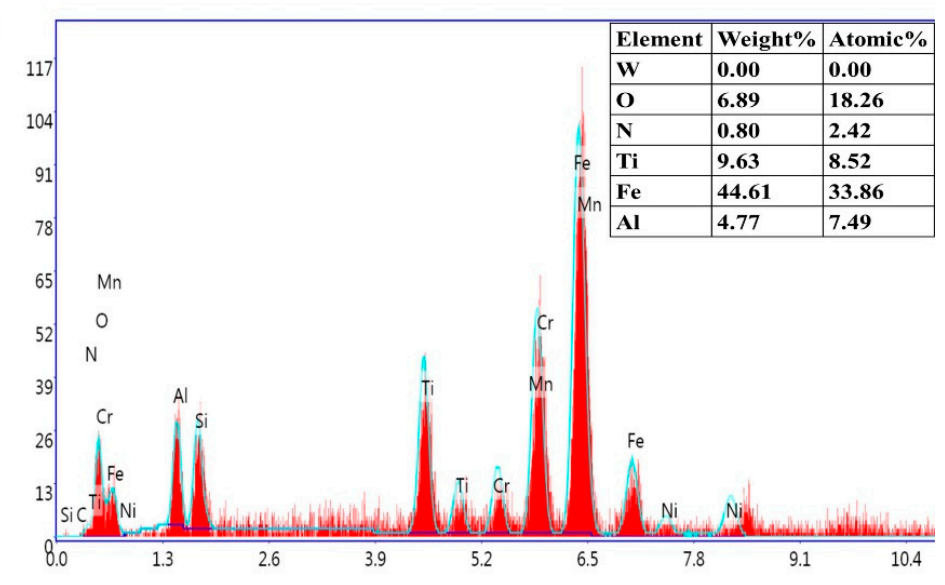

Figure 11. Cont. 


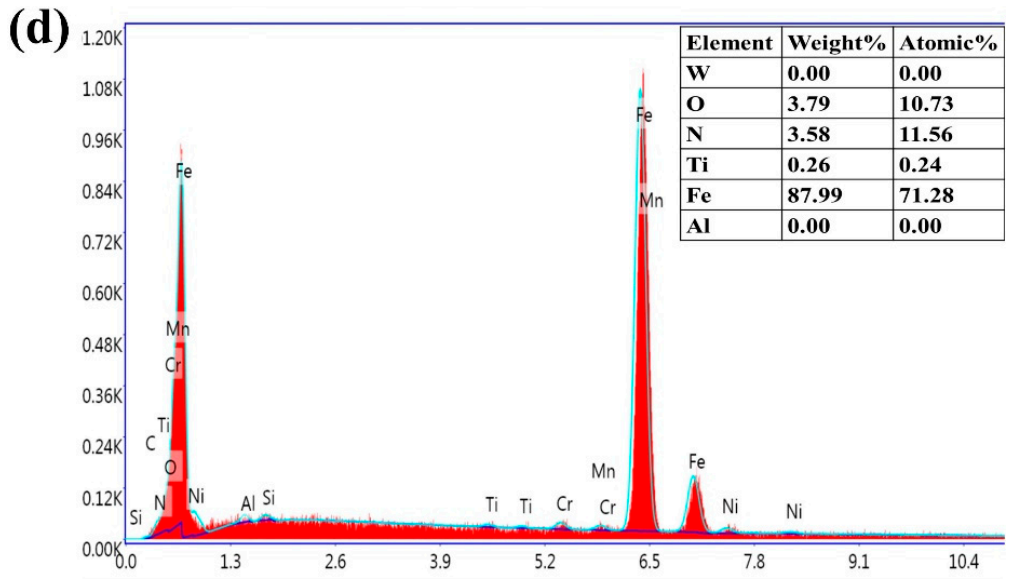

Figure 11. EDS analysis at $v_{\mathrm{c}}=440 \mathrm{~m} / \mathrm{min}, f_{\mathrm{z}}=0.04 \mathrm{~mm} / \mathrm{z}, a_{\mathrm{p}}=0.4 \mathrm{~mm}$, and $a_{\mathrm{e}}=4 \mathrm{~mm}$. (a) Area A in Figure 10a. (b) Area B in Figure 10b. (c) Area C in Figure 10c. (d) Area D in Figure 10d.

Moreover, the Fe element that diffused from the workpiece is tested on the worn surface (Figure 11). It is suggested that the adhesive layer is formed on the flank face. However, the adhesive layer is unstable, which can cause the flaking of coating on the flank face and accelerate tool wear. Thus, it is proven that the adhesion is an important cause of tool wear.

The content of the Fe element on the flank face of the TiN/TiCN/TiAlN multi-coated tool is the lowest (Figure 11a), while the flank wear width is minimal and the wear form is single (Figure 10a). The content of the Fe element on the flank face of the TiCN + NbC coated tool is the highest (Figure 11d), while the flank wear is the most serious (Figure 10d). It is concluded that the wear states of coated tools are related to the content of the Fe element. Because of the diffusion of the Fe element, the strength of the coated tool is seriously reduced, which results in sharpening, chipping, and peeling. Therefore, it could be inferred that the Fe element accelerates tool wear in high-speed milling of AISI 4340.

In summary, the cutting performance of the TiN/TiCN/TiAlN multi-coated tool is the best among the four coated tools. First, the chip surface gained by TiN/TiCN/TiAlN multi-coated tools is the smoothest. Second, the cutting force of the TiN/TiCN/TiAlN multi-coated tool is minimal. Third, the high heat dissipation performance of the TiN/TiCN/TiAlN multi-coated tool contributed the lower cutting temperature. Lastly, the flank wear width of the TiN/TiCN/TiAlN multi-coated tool is minimal.

\section{Conclusions}

- The burrs and the smoothness's degree of chip surfaces flowing from the rake face can reflect tool wear. Generally, the dense burrs and non-smooth chip surface are acquired in the condition of serious tool wear. The chip surfaces flowing from the rake face obtained by the TiN/TiCN/TiAlN multi-coated tool is the smoothest, and the flank wear width of the TiN/TiCN/TiAlN multi-coated tool is minimal.

- The cutting force $\left(F_{\mathrm{x}}, F_{\mathrm{y}}, F_{\mathrm{z}}\right)$ is improved with the increase of the cutting parameter $\left(v_{\mathrm{c}}, f_{\mathrm{z}}, a_{\mathrm{p}}\right.$, and $a_{\mathrm{e}}$ ). The $F_{\mathrm{Z}}$ (axial force) is the main cutting force. The value of $F_{\mathrm{Z}}$ is the maximum cutting force component when the coated tools are used for high-speed milling of AISI 4340 steel.

- $\quad \mathrm{TiCN}$, as the middle layer of the coated tool, can improve heat dissipation of the coated tool. This is also the reason why the TiN/TiCN/TiAlN multi-coated tool has the lowest cutting temperature. However, the heat dissipation of $\mathrm{TiCN}$ is reduced when $\mathrm{TiCN}$ and $\mathrm{NbC}$ act as the composite coating.

- The flank wear of the coated tools is the dominant wear type in high-speed milling of AISI 4340 steel. The chipping of coating, abrasive wear, collapse, and chipping are the dominant wear mechanisms. The flank wear of the TiN/TiCN/TiAlN multi-coated tool is lower than that of the other three tools. 
- Among the four coated tools, the TiN/TiCN/TiAlN multi-coated tool is the most suitable for the high-speed milling of AISI 4340, because of the smallest cutting force and the lowest cutting temperature, which could achieve minimal flank wear.

Author Contributions: Conceptualization and writing-review and editing, G.Z. Formal analysis and writing-original draft preparation, Y.L. Software and data curation, X.C. Investigation, X.Y. Validation, R.X. Supervision, H.Z.

Funding: The National Key Research and Development Program of China (No. 2018YFB2001400), the Project funded by China Postdoctoral Science Foundation (No. 2019M652439), the National Natural Science Foundation of China (No. 51505264), and the Zibo City-Shandong University of Technology Cooperative Projects (No. 2018ZBXC003) supported this work.

Acknowledgments: We give thanks to X.J. Liu for grammar revision.

Conflicts of Interest: The authors declare no conflict of interest.

\section{References}

1. Xu, Q.; Zhao, J.; Ai, X. Fabrication and cutting performance of Ti(C,N)-based cermet tools used for machining of high-strength steels. Ceram. Int. 2017, 43, 6286-6294. [CrossRef]

2. Singh, R.; Dureja, J.S.; Dogra, M. Performance evaluation of textured carbide tools under environment-friendly minimum quantity lubrication turning strategies. J. Braz. Soc. Mech. Sci. Eng. 2019, 41, 87. [CrossRef]

3. Pereira, J.C.C.; Rodrigues, P.C.M.; Abrão, A.M. The surface integrity of AISI 1010 and AISI 4340 steels subjected to face milling. J. Braz. Soc. Mech. Sci. Eng. 2017, 39, 4069-4080. [CrossRef]

4. Sahoo, A.K.; Sahoo, B. Experimental investigations on machinability aspects in finish hard turning of AISI 4340 steel using uncoated and multilayer coated carbide inserts. Measurement 2012, 45, 2153-2165. [CrossRef]

5. Jhodkar, D.; Amarnath, M.; Chelladurai, H.; Ramkumar, J. Experimental investigations to enhance the machining performance of tungsten carbide tool insert using microwave treatment process. J. Braz. Soc. Mech. Sci. Eng. 2018, 40, 200. [CrossRef]

6. Chinchanikar, S.; Choudhury, S.K. Investigations on machinability aspects of hardened AISI 4340 steel at different levels of hardness using coated carbide tools. Int. J. Refract. Met. Hard Mater. 2013, 38, 124-133. [CrossRef]

7. Das, R.K.; Sahoo, A.K.; Mishra, P.C.; Kumar, R.; Panda, A. Comparative machinability performance of heat treated 4340 steel under dry and minimum quantity lubrication surroundings. Procedia Manuf. 2018, 20, 377-385. [CrossRef]

8. Zhang, S.; Guo, Y.B. An experimental and analytical analysis on chip morphology, phase transformation, oxidation, and their relationships in finish hard milling. Int. J. Mach. Tools Manuf. 2009, 49, 805-813. [CrossRef]

9. Li, B. Chip morphology of normalized steel when machining in different atmospheres with ceramic composite tool. Int. J. Mach. Tools Manuf. 2011, 29, 384-391. [CrossRef]

10. Singh, B.K.; Roy, H.; Mondal, B.; Roy, S.S.; Mandal, N. Measurement of chip morphology and multi criteria optimization of turning parameters for machining of AISI 4340 steel using Y-ZTA cutting insert. Measurement 2019, 142, 181-194. [CrossRef]

11. Suresh, R.; Basavarajappa, S.; Gaitonde, V.N.; Samuel, G.L. Machinability investigations on hardened AISI 4340 steel using coated carbide insert. Int. J. Refract. Met. Hard Mater. 2012, 33, 75-86. [CrossRef]

12. Yang, X.; Cao, H.J.; Chen, Y.P.; Zhu, L.B.; Li, B.J. An analytical model of chip heat-carrying capacity for high-speed dry hobbing based on 3D chip geometry. Int. J. Precis. Eng. Manuf. 2017, 18, 245-256. [CrossRef]

13. Dasa, S.R.; Pandab, A.; Dhupal, D. Hard turning of AISI 4340 steel using coated carbide insert: Surface roughness, tool wear, chip morphology and cost estimation. Mater. Today Proc. 2018, 5, 6560-6569.

14. Cui, X.B.; Zhao, B.; Jiao, F.; Zheng, J.X. Chip formation and its effects on cutting force, tool temperature, tool stress, and cutting edge wear in high- and ultra-high-speed milling. Int. J. Adv. Manuf. Technol. 2016, 83, 55-65. [CrossRef]

15. Kumar, C.S.; Patel, S.K. Effect of chip sliding velocity and temperature on the wear behaviour of PVD AlCrN and AlTiN coated mixed alumina cutting tools during turning of hardened steel. Surf. Coat. Technol. 2018, 334, 509-525. [CrossRef] 
16. Zhang, X.P.; Wu, S.B. Chip control in the dry machining of hardened AISI 1045 steel. Int. J. Adv. Manuf. Technol. 2017, 88, 3319-3327. [CrossRef]

17. Mandal, N.; Doloi, B.; Mondal, B. Force prediction model of zirconia toughened alumina (ZTA) inserts in hard turning of AISI 4340 steel using response surface methodology. Int. J. Precis. Eng. Manuf. 2012, 13, 1589-1599. [CrossRef]

18. Zheng, G.M.; Xu, R.F.; Cheng, X.; Zhao, G.Y.; Li, L.; Zhao, J. Effect of cutting parameters on wear behavior of coated tool and surface roughness in high-speed turning of 300M. Measurement 2018, 125, 99-108. [CrossRef]

19. Patole, P.B.; Kulkarni, V.V. Optimization of process parameters based on surface roughness and cutting force in MQL turning of AISI 4340 using Nano fluid. Mater. Today Proc. 2018, 5, 104-112. [CrossRef]

20. Beake, B.D.; Endrino, J.L.; Kimpton, C.; Fox-Rabinovich, G.S.; Veldhuis, S.C. Elevated temperature repetitive micro-scratch testing of AlCrN, TiAlN and AlTiN PVD coatings. Int. J. Refract. Met. Hard Mater. 2017, 69, 215-226. [CrossRef]

21. Zhang, H.P.; Zhang, Q.Y.; Ren, Y.; Shay, T.; Liu, G.L. Simulation and experiments on cutting forces and cutting temperature in high speed milling of 300M steel under CMQL and dry conditions. Int. J. Precis. Eng. Manuf. 2018, 19, 1245-1251. [CrossRef]

22. Chinchanikar, S.; Choudhury, S.K. Evaluation of chip-tool interface temperature: Effect of tool coating and cutting parameters during turning hardened AISI 4340 steel. Procedia Mater. Sci. 2014, 6, 996-1005. [CrossRef]

23. Zhao, J.F.; Liu, Z.Q. Effects of thermo-physical properties of Ti0.41A10.59N coating on transient and steady cutting temperature distributions in coated cemented carbide tools. Int. Commun. Heat Mass Transf. 2018, 96, 80-89. [CrossRef]

24. Gupta, K.M.; Ramdev, K.; Dharmateja, S.; Sivarajan, S. Cutting characteristics of PVD coated cutting tools. Mater. Today Proc. 2018, 5, 11260-11267. [CrossRef]

25. Cakan, A. Real-time monitoring of flank wear behavior of ceramic cutting tool in turning hardened steels. Int. J. Adv. Manuf. Technol. 2011, 52, 897-903. [CrossRef]

26. Chinchanikar, S.; Choudhury, S.K. Predictive modeling for flank wear progression of coated carbide tool in turning hardened steel under practical machining conditions. Int. J. Adv. Manuf. Technol. 2015, 76, 1185-1201. [CrossRef]

27. Ginting, A.; Skein, R.; Cuaca, D.; Herdianto; Pieter; Masyithah, Z. The characteristics of CVD- and PVD-coated carbide tools in hard turning of AISI 4340. Measurement 2018, 129, 548-557. [CrossRef]

28. Kumar, C.S.; Patel, S.K. Performance analysis and comparative assessment of nano-composite TiAlSiN/TiSiN/TiAlN coating in hard turning of AISI 52100 steel. Surf. Coat. Technol. 2018, 335, 265-279. [CrossRef]

29. Li, N.; Chen, Y.J.; Kong, D.D. Wear mechanism analysis and its effects on the cutting performance of PCBN inserts during turning of hardened 42CrMo. Int. J. Precis. Eng. Manuf. 2018, 19, 1355-1368. [CrossRef]

30. Boing, D.; Oliveira, A.J.; Schroeter, R.B. Limiting conditions for application of PVD (TiAlN) and CVD (TiCN/Al2O3/TiN) coated cemented carbide grades in the turning of hardened steels. Wear 2018, 416-417, 54-61. [CrossRef]

31. Zhang, Q.; Xu, Y.X.; Zhang, T.F.; Wu, Z.T.; Wang, Q.M. Tribological properties, oxidation resistance and turning performance of AlTiN/AlCrSiN multilayer coatings by arc ion plating. Surf. Coat. Technol. 2018, 356, 1-10. [CrossRef]

32. Zheng, G.M.; Cheng, X.; Li, L.; Xu, R.F.; Tian, Y.B. Experimental investigation of cutting force, surface roughness and tool wear in high-speed dry milling of AISI 4340 steel. J. Mech. Sci. Technol. 2019, 33, 341-349. [CrossRef]

33. Available online: https://www.kennametal.com/content/dam/kennametal/kennametal/zh/Resources/CatalogsLiterature/Metalworking/A-12-02809_ToolingSystems13_ZH_LR.pdf (accessed on 19 September 2019).

34. Available online: https://www.sumitool.com/cn/downloads/cutting-tools/general-catalog/assets/pdf/h1.pdf (accessed on 19 September 2019).

35. Available online: https://www.kyocera.com.cn/prdct/cuttingtool/wp-content/uploads/2018/04/MEC.pdf (accessed on 19 September 2019). 
36. China Aeronautical Materials Handbook Editorial Committee. China Aeronautical Materials Handbook; China Standards Press: Beijing, China, 2001.

37. Grzesik, W. Advanced Protective Coatings for Manufacturing and Engineering; Hanser Gardner Publications: Cincinnati, OH, USA, 2003. 